\title{
Awareness of breast cancer risk factors and practice of breast self examination among female undergraduates in university of Nigeria Enugu campus
}

\author{
Peace Iheanacho ${ }^{1}$, Afam Ndu ${ }^{2}$, Amaka Doris Emenike ${ }^{2}$ \\ ${ }^{1}$ University of Nigeria, Enugu Campus, Enugu, Nigeria \\ ${ }^{2}$ School of Psychiatric and Mental Health, Federal Neuropsychiatric Hospital, Enugu, Nigeria \\ Email: afamci@yahoo.com
}

Received 28 January 2013; revised 4 March 2013; accepted 13 March 2013

\begin{abstract}
Breast cancer patients generally have low rates of survival due to being diagnosed at advanced stages raising critical issues about prevention and avoidance of risk factors. Breast self examination makes women more "breast aware", which in turn may lead to an earlier diagnosis of breast cancer. In Nigeria, the statistics of breast cancer have overtaken cancer of the cervix to become the commonest malignancy in women. This study was carried out to determine the awareness of breast cancer risk factors and practice of breast self examination among female students of the University of Nigeria Enugu Campus. The descriptive survey design was used for the study. The population of the study was all the female students that reside in hostels in the campus (2400) in number. A sample of 240 students was selected using quota sampling technique. Structured questionnaires based on the research objectives were used for data collection. The results of the study showed that most of the students have little knowledge of breast cancer risk factors and majority of the students do not practice BSE monthly. It was recommended that there should be regular organization of seminars and workshops for students to address sensitive topics like breast cancer risk factors and breast self examination.
\end{abstract}

Keywords: Risk Factors; Breast Cancer; Breast Self Examination

\section{INTRODUCTION}

Breast cancer is the commonest malignant condition afflicting females all over the world. Recent global cancer statistics indicate a rising incidence of breast cancer making it the commonest cancer not only in developed countries but also in developing world too that hitherto enjoyed a low incidence of the disease (Puri, Bhatia,
Kalia, Sehgal and Kaur, 2009) [1]. It has been reported that each year over 1.5 million women worldwide are diagnosed with breast cancer and 502,000 die from the disease. The incidence could go up by 50\% i.e. 1.5 million by 2020 according to world cancer report 2008 (Puri et al., 2009). In 2011, an estimated 230,480 new cases of invasive breast cancer will be diagnosed among women, as well as an estimated 57,650 additional cases of in situ breast cancer. In 2011, approximately 39,520 women are expected to die from breast cancer. Only lung cancer accounts for more cancer deaths in women. In 2011, about 2140 cases of breast cancer are expected to occur among men, accounting for about $1 \%$ of all breast cancers. In addition, approximately 450 men will die from breast cancer (American Cancer Society, 2011) [2]. In Nigeria, the statistics of breast cancer have overtaken cancer of the cervix to become the commonest malignancy in women (Adebamowo and Ajayi, 2000) [3]. Over the years, various attempts have been made at either preventing breast cancer when it does occur (Okojie, Osime, Amigbekaen, 2008). Of prime importance are the "breast awareness" and the ability to identify of breast cancer risk factors which go a long way to help in the early diagnosis of breast cancer.

Awareness and knowledge about breast cancer vary among communities and population groups worldwide. While studies conducted to assess breast cancer knowledge among women showed satisfactory levels in some places (Grunfeld, Ramirex, Huner, Richards, 2002 [4]; Mcmenamin, Barry, Lennon, Purcel, et al., 2005), other reports especially from developing countries like Nigeria reveal inadequate knowledge and awareness about the disease (Okobia, Bunker, Okonofua and Osime 2006) [5]. Whereas patients in communities with high level of awareness usually present with less advanced stages of breast cancers as a result of adoption of screening methods (Parkin, Bray, Ferley, 2002) [6], those in communities with low level of awareness often present late 
(Grunfeld et al., 2002) [4]. This has implication for treatment success and patient survival.

In view of these facts, the researchers, in the course of clinical work, have observed that younger women are developing breast cancer; few of them undergo lumpectomy while others end up with mastectomy due to the advanced stages of the cancer at presentation, and of course, the attendant consequences.

Secondly, with the increasing incidence of young women in other parts of the world adopting western lifestyle (Rosenberg, Levy-schwartz, 2003) [7,8], it has been observed that more young women are now being exposed to some of the modifiable breast cancer risk factors like the use of contraceptive pills, nulliparity, advancing age at first child birth, alcohol consumption, high fat diet, smoking, obesity and so forth. One wonders whether these young women as represented by female university undergraduates are aware of the fact that some of these so called lifestyles habits and practices constitute risk factors for breast cancer.

Breast self examination is a cost-effective and cheap method of early detection of breast cancer, could it be that these young women do not practice breast self examination regularly, which has been shown to play a major role in early detection of breast cancer. For young women, breast self examination education and adherence are health promotion behaviours which set the stage for adherence to clinical breast examination and mammography screening later in life (Rosenberg and LevySchwartz, 2003) $[7,8]$. There is also need to assess the current level knowledge of breast cancer risk factors and practice of screening methods among women. This would help in determining the need for continuing medical and health education programmes that could improve knowledge of the disease and adoption of early detection measures by these women. This will not only enhance their positive influence on women but also improve their individual level of breast cancer risk factors awareness.

The American Cancer Society (2008) [9] recommends an option breast cancer risk factors awareness and breasts self examination for early detection of breast cancer. It benefits women in two ways. Women become familiar with both the appearance and the feel of their breasts and detect any change in their breast as early as possible. Breast self examination makes women more "breast aware" which in turn may lead to an earler diagnosis of breast cancer (Siahpush and Sigh, 2002) [10]. The rationale behind extending breast self examination practice as a screening test is the fact that breast cancer is frequently detected by women themselves without any other symptoms (Levshin, Fedichkina and Droggachih, 1998) [11].

It was on this premise that the researchers decided to carry out this study on female undergraduates in University of Nigeria Enugu Campus because they fall within the age limits of these young women. The purpose of the study was to assess the awareness of breast cancer risk factors and the practice of breast self examination among the students with a view to generating evidence based information for health education on breast cancer and suggestions made in areas of deficiencies. Specifically, the objectives of the study are to: 1) assess the knowledge of breast cancer risk factors among female undergraduates; 2) determine student's knowledge of breast self-examination; 3) determine student's breast self examination practices; 4) determine the attitude of the female students towards breast self examination and 5) identify students' sources of information on BSE and breast cancer risk factors.

\section{METHODS AND MATERIALS}

The descriptive survey method was used for the study. There were seven (7) female hostels in the campus and all were included in the study. A total of two thousand four hundred students reside in these hotels.

A sample of two hundred and forty (240) students was selected from the population. Quota sampling method was used to select 240 respondents from the seven female hostels in the University to ensure even representation. Subsequently, individual students were selected from each of these seven hostels by convenient sampling, until the quota for each hostel was obtained.

The instrument for data collection was the questionnaire which was designed by the researchers. It was made up of 4 sections. Section A was for demographic variables while Section B, C and D contained items to elicit information on the stated objectives (research questions). The items were structured in a close-ended format.

An informed consent form was signed by each of the subjects following thorough explanation of the purpose, process, demands and requirements of the study.

220 copies of the questionnaire were returned well completed, out of the 240 copies distributed giving a response rate of $92 \%$.

\section{RESULTS}

\subsection{Demographic Data}

Forty-one (19\%) are within the age range of $16-19$ years, one hundred and twenty (55\%) are within the age range of $20-23$, forty-seven (21\%) are within the age range of $24-27$, twelve (5\%) are within the age range of 28 - 31. none is within the age range of 32 and above. Twenty eight $(13 \%)$ are in $1^{\text {st }}$ year, sixty one $(28 \%)$ in $2^{\text {nd }}$ year, thirty eight $(17 \%)$ in $3^{\text {rd }}$ year, forty-four $(25 \%)$ in 
$4^{\text {th }}$ year and thirty-nine $(18 \%)$ in $5^{\text {th }}$ year. Two hundred and eight (95\%) were single and twelve (5\%) were married. $32(15 \%)$ were in Medicine, 81 (37\%) in Health Sciences. 29 (13\%) in Law, 56 (25\%) in Business Administrational and $22(10 \%)$ in Environmental Sciences. $192(87 \%)$ were of the Igbo tribe, 11 (5\%) were Yoruba, 2 (0.9\%) were Hausas and 15 (7\%) were from other ethnic groups like the Niger delta (river-rine) areas.

\subsection{Knowledge of Breast Cancer Risk Factors among Female Undergraduates in UNEC}

192 (87\%) of the were reported being aware that there are risk factors to breast cancer and 28 (13\%) claimed they have never heard about it. 134 students (60\%) knew that risk factors were things that increase someone's likelihood of developing a disease; 44 students (20\%) felt that risk factors are the causes of a disease, $14 \mathrm{stu}-$ dents (6\%) thought they were disease-causing organisms. The respondents were asked to identify as many things as they consider risk factors from a list. The following factors were identified in decreasing order of frequency: family history (109 students (50\%)); high radiations to the chest wall, (86 (39\%)); tobacco smoking, (80 (36\%)); drug abuse (62 students or 28\%); personal history of breast cancer (60 students (27\%)); blow (trauma) to the breast, $(60 \%$ or $27 \%)$; alcohol intake (43 students $(20 \%)$ ); repeated abortions (42 students or 19\%); never having breastfed a child, (39 students (18\%)); high fat diet, 38 (17\%); aging, (38 students (17\%); and obesity, (37 (17\%)) etc. (see Table 1).

\subsection{Students' Knowledge of Breast Self Examination}

205 students (93\%) have heard of and understand the meaning of BSE while 15 (7\%) claimed they have never heard of BSE.

Table 2 shows that 28 students (13\%) reported that BSE should be performed weekly, 120 students (55\%) reported monthly, 3 students (1\%) reported yearly and 62 students (28\%) reported anytime.

From the Table 3, 80 students (36\%) have knowledge on the appropriate time for BSE, 47 (21\%) reported at the beginning of the month, $40(18 \%)$ reported before the onset of menstrual period and 4 (2\%) reported when one is not feeling fine.

Concerning knowledge of who should perform BSE, 193 students (88\%) correctly reported that every woman that has reached puberty should perform BSE, 4 students (2\%) reported that BSE should be performed by women 60 years and above, 6 students (3\%) reported only adolescents, 9 students (4\%) reported that it is women between 30 - 60 years of age and Table 4 shows that 48 students (22\%) reported that there are 3 steps in BSE, 48
Table 1. Knowledge of breast cancer risk factors.

\begin{tabular}{|c|c|c|c|}
\hline & Possible risk factors & $\mathrm{F}$ & $\%$ \\
\hline A & Family history of breast cancer & 109 & 50 \\
\hline B & Personal history of breast cancer. & 60 & 27 \\
\hline $\mathrm{C}$ & Early menarche (before 12 years) & 12 & 6 \\
\hline $\mathrm{D}$ & Late menopause (if ones menses stops late) & 26 & 12 \\
\hline $\mathrm{F}$ & Aging & 38 & 17 \\
\hline G & Alcohol intake & 43 & 20 \\
\hline $\mathrm{H}$ & Repeated abortions & 42 & 19 \\
\hline I & Not giving birth at all (nulliparity) & 20 & 9 \\
\hline $\mathrm{J}$ & Having first baby after age 30 & 15 & 7 \\
\hline $\mathrm{K}$ & Breast feeding for at least 18 months & 13 & 6 \\
\hline $\mathrm{L}$ & Early sexual debut & 24 & 11 \\
\hline M & Never breast fed a child & 39 & 18 \\
\hline $\mathrm{N}$ & High fat diet & 38 & 17 \\
\hline $\mathrm{O}$ & Obesity & 37 & 17 \\
\hline $\mathrm{P}$ & Promiscuity & 16 & 7 \\
\hline $\mathrm{Q}$ & Witchcraft attacks & 6 & 3 \\
\hline $\mathrm{R}$ & Blow (trauma) to the breast & 60 & 27 \\
\hline $\mathrm{S}$ & Tobacco smoking & 80 & 36 \\
\hline $\mathrm{T}$ & Having too many children & 4 & 2 \\
\hline $\mathrm{U}$ & Drug abuse & 62 & 28 \\
\hline $\mathrm{V}$ & High radiations to the chest & 86 & 39 \\
\hline W & Lack of physical exercise & 20 & 9 \\
\hline $\mathrm{X}$ & Too much touching and fondling of the breast & 26 & 12 \\
\hline $\mathrm{Y}$ & Wrath of god & 4 & 2 \\
\hline $\mathrm{Z}$ & Being too slim & 1 & 0.5 \\
\hline
\end{tabular}

Table 2. Knowledge of frequency of BSE.

\begin{tabular}{ccc}
\hline How often should BSE be performed & F & $\%$ \\
\hline Weekly & 28 & 13 \\
Monthly & 120 & 55 \\
Yearly & 3 & 1 \\
Anytime & 62 & 28 \\
\hline
\end{tabular}

Table 3. Timing of BSE.

\begin{tabular}{ccc}
\hline At what time should BSE be done? & F & $\%$ \\
\hline At the beginning of every month & 47 & 21 \\
When one is not feeling fine & 4 & 2 \\
5 - 7 days after menstrual period & 80 & 36 \\
5 - 7 days before the onset of menstrual period & 40 & 18 \\
Total & 171 & 77 \\
\hline
\end{tabular}


Table 4. (a) How many steps involved in BSE? (b) Which part of the hand is used to perform BSE?

(a)

\begin{tabular}{ccc}
\hline How many steps are there in BSE? & F & $\%$ \\
\hline 3 & 48 & 22 \\
4 & 48 & 22 \\
5 & 29 & 13 \\
6 & 10 & 5 \\
Don't know & 77 & 35 \\
Total & 212 & 97 \\
\hline
\end{tabular}

(b)

\begin{tabular}{cccc}
\hline & BSE is done with which part of the hand & F & $\%$ \\
\hline a & The whole of the fingers & 37 & 17 \\
b & The $2^{\text {nd }}, 3^{\text {rd }}$ and $4^{\text {th }}$ finger pads. & 98 & 45 \\
c & The palm of the hand & 24 & 11 \\
d & One or two fingers & 29 & 13 \\
& No response & 32 & 14 \\
& Total & 220 & 100 \\
\hline
\end{tabular}

students (22\%) reported 4 steps, 29 (13\%) reported 5 steps, 10 students (5\%) reported 6 steps and about 77 students (35\%) reported that they don't know.

Table 4 shows that 37 students (17\%) reported that BSE is done using the whole of the fingers, 98 (45\%) reported on the $2^{\text {nd }}, 3^{\text {rd }}$ and $4^{\text {th }}$ fingers pads, $24(11 \%)$ reported the palm of the hand, and 29 students (13\%) reported on one or two fingers.

\subsection{Students' Breast Self Examination Practice}

165 students (73\%) reported that they perform BSE and 55 (25\%) do not perform BSE 54 students (25\%) reported performing BSE every month, 8 students (4\%) perform every week, and 89 students (40\%) perform the procedure whenever they remember and 12 students (5\%) perform the procedure every month (Table 5).

Table 6 was on the reasons for not performing BSE: 28 students (13\%) reported "Not knowing how to perform", 11 students (5\%) reported "Not expecting to get breast cancer" 5 (2\%) don't think it is important. 3 students (1\%) reported on "Not in my family", 5 students (2\%) reported on "Not knowing the reason for performing BSE" and 5 students (2\%) reported on other reasons like "Do not always remember".

From the above Table 7189 students (86\%) look out for lumps, 45 students (21\%) look out for secretions form the nipple, 31 students (14\%) look out for dimpling of the skin of the breast and 25 students (11\%) look out for nipple that s sucked in retracted nipple).
Table 5. How often students practice BSE.

\begin{tabular}{cccc}
\hline & How often & F & $\%$ \\
\hline a & Every month & 54 & 25 \\
b & Every week & 8 & 4 \\
c & Whenever I remember & 89 & 40 \\
d & Every other month & 12 & 5 \\
& Total & 163 & 75 \\
\hline
\end{tabular}

Table 6. Reasons for not performing BSE.

\begin{tabular}{cccc}
\hline & & F & $\%$ \\
\hline a & Not knowing how to perform & 28 & 13 \\
b & Not expecting to get breast cancers & 11 & 5 \\
c & Don't think it is important & 5 & 2 \\
d & Not in my family & 3 & 1 \\
e & Not knowing the reasons for performing BSE & 5 & 2 \\
f & Others reasons & 5 & 2 \\
& Total & 56 & 25 \\
\hline
\end{tabular}

Table 7. What students look out for when examining the breast.

\begin{tabular}{|c|c|c|c|}
\hline & $\begin{array}{l}\text { What do you look out for when } \\
\text { examining your breast? }\end{array}$ & $\mathrm{F}$ & $\%$ \\
\hline $\mathrm{a}$ & Lumps (swelling, feeling hard nut) & 189 & 86 \\
\hline $\mathrm{b}$ & Secretions from nipple & 45 & 21 \\
\hline c & Dimpling of the skin of the breast & 31 & 14 \\
\hline d & Nipple that is sucked in (retraction) & 25 & 11 \\
\hline
\end{tabular}

\subsection{Student's Attitude towards BSE}

From the above Table 8, 193 students (88\%) reported that they can encourage their friends to practice BSE, 10 (5\%) reported that they cannot do it. 214 students (97\%) believe that practice of BSE helps in early detection of abnormal changes in the breast while 6 students (3\%) do not agree with this. 143 students (65\%) reported that monthly practice of BSE is very important while 7 students (3\%) reported that it is not important. 210 students (95\%) agree that practice of BSE is not a waste of time while 5 students (2\%) reported that it is a waste of time.

Major sources of information as shown on the table include: print media, electronic media school and health care providers (Table 9).

\section{DISCUSSION}

The findings of this study revealed that students had little knowledge of the associated breast cancer risk factors. 
Table 8. Attitude of female students in UNEC towards BSE.

\begin{tabular}{cccccc}
\hline & \multicolumn{3}{c}{ Yes } & \multicolumn{2}{c}{ No } \\
\cline { 3 - 6 } & F & $\%$ & F & $\%$ \\
\hline a & $\begin{array}{c}\text { Can you encourage your friend } \\
\text { to practice BSE? }\end{array}$ & 193 & 88 & 10 & 5 \\
b $\quad \begin{array}{c}\text { Do you think that BSE helps in } \\
\text { early detection of abnormal } \\
\text { changes in the breast? }\end{array}$ & 214 & 97 & 6 & 3 \\
$\quad \begin{array}{c}\text { Do you think that monthly practice } \\
\text { of BSE in very important? }\end{array}$ & 143 & 65 & 7 & 3 \\
d $\quad \begin{array}{c}\text { Do you consider the practice of } \\
\text { BSE is a waste of time? }\end{array}$ & 5 & 2 & 210 & 95 \\
\hline
\end{tabular}

Table 9. Sources of information on BSE and breast cancer risk factors.

\begin{tabular}{cccc}
\hline & Sources of information & F & $\%$ \\
\hline a & Health care providers (doctors, nurses) & 140 & 64 \\
b & School (lecturers, friends) & 145 & 66 \\
c & Books & 150 & 68 \\
d & Posters & 75 & 34 \\
e & Church (seminars) & 43 & 20 \\
f & Internet & 85 & 39 \\
g & Electronic media (television, radio etc.) & 149 & 68 \\
h & Hand bills & 50 & 23 \\
i & Others & 6 & 3 \\
\hline
\end{tabular}

The results showed that the only risk factors that are widely known are family history of breast cancer (50\%), and tobacco smoking (36\%). The findings also showed that very few students had knowledge of other risk factors (obesity, alcohol intake, early menarche, nulliparity, breastfeeding for at least 18 months) as possible risk factors for breast cancer. Although the respondents' major sources of information were from books and electronic media, the probable explanation for this insufficient knowledge on breast cancer risk factors is that the information they have is not complete. The findings of this study agree with the finding of the study carried out by Karagurt (2007) which showed that the students had little knowledge of the risk factors for breast cancer and that the most widely known risk factors were family history of breast cancer and personal history of breast cancer. The results of this study also agree with that of Peacey, Steptoe et al. (2006) where nearly one third of the respondents were not aware of the factors that influence breast cancer.

The results of this study imply that there is insufficient knowledge on the possible risk factors for breast cancer and this could indirectly contribute to the increasing number of younger people coming down with breast cancer since they lack knowledge of knowledge of the simplest cheapest method of minimizing the menace of breast cancer, while, of course, some of them still engage in those practices that are considered risky.

With regard to student's knowledge of BSE, results showed that the majority of respondents studied reported awareness of BSE, and knew that BSE should be performed by every woman who has reached puberty. However, subsequent findings show that fewer and fewer students actually understand the procedures involved in BSE. Results show that there is poor knowledge of other areas of BSE as only 120 (55\%) had knowledge of the frequency of BSE, 80 (36\%) have knowledge of the appropriate timing for BSE, 77 (35\%) of respondents did not know the number of steps involved in BSE and only $98(45 \%)$ reported correctly that BSE should be done with the $2^{\text {nd }}, 3^{\text {rd }}$, and $4^{\text {th }}$ finer pads.

Generally, this shows that there is poor knowledge of BSE among female undergraduates in UNEC. The result of this study corresponds with that of Aniebue and Aniebue (2008), who reported that only $26.9 \%$ of the respondents possess adequate knowledge for BSE. Also Milaat (2000) reported that only $14.4 \%$ of secondary school female nursing students have knowledge about the frequency of BSE and that $7.1 \%$ of the students have knowledge about appropriate time for BSE.

The findings of this study also agree with that of Karagurt (2007) who stated that $66 \%$ of students do not have knowledge about frequency of BSE, $75.4 \%$ of students do not have knowledge about the appropriate time for BSE and $65.4 \%$ of students do not have knowledge of BSE procedure.

The result of all these studies reviewed showed that there is poor knowledge of BSE worldwide. This can help to understand the increasing rate of development of breast cancer.

Also, concerning practice, $73 \%$ of students perform BSE but only $25 \%$ perform BSE monthly, $40 \%$ of the students were performing irregularly. Students' knowledge about BSE might have affected their performance. It is not possible to practice what one does not know about. In other studies, the percentage of monthly BSE performance have been found to be $3.4 \%$ among teenagers (Ludwick and Gaczkowki, 2001) [12], 14.8\% among students aged 17 to 30 years in Europe (Steptoe, Smith, Koller et al., 2005), and 27\% among female nursing students (Budden, 2000). These studies suggest that the percentage of adolescents performing BSE monthly is low all over the world. As observed from these studies, if the rate of performance of BSE continues to be low then there will always is a high incidence of development of breast cancer all over the world. 
Attitude of Female Students towards BSE

Student's attitude was assessed by asking them a few questions to answer yes or no in order to determine their disposition to the issue under consideration. From the result on Table 8, majority of the students (88\%) agreed that they can encourage their friends to practice BSE. $97 \%$ of students agreed that the practice of BSE helps in early detection of abnormal changes in the breast. 65\% of the students indicated that BSE is very important and 95\% disagrees that practice of BSE is a waste of time.

These findings support the report from a recent study carried out on women from a semi-urban neighborhood in Southern Nigeria, in which Okobia et al. (2006) reported that $51 \%$ of participants believed that BSE is very important and that breast cancer in curable if detected early through the practice of BSE.

This finding implies a positive attitude which if people develop; they will be more likely to practice BSE for early detection of breast cancer. This will in turn help in reducing the rate of late stage diagnosis of breast cancers. In other words, if there is negative attitude toward breast cancer and resultant poor practice of BSE, the rate of development of breast cancer will continue to rise.

Sources of Information

The data also showed that majority of the students had acquired information about breast cancer, its risk factors and BSE from sources such as media, from books, school (lectures, friends) and from health care providers. This result is consistent with the results of the other studies like Budden (1995) [13] and Milaat (2000) [14]. These findings indicated that media continue to be one of the most important sources of information about breast cancer and BSE and highlighted the cooperation between public health educators and the media in dissemination of breast cancer information and BSE.

\section{CONCLUSION}

The findings of this research work showed that there is low level of knowledge on breast cancer risk factors and BSE among the students of UNEC and that only few students practice BSE monthly. This shows that there is need for more public enlightenment on breast cancer risk factors and importance of BSE especially among students.

\section{REFERENCES}

[1] Puri, S., Mangat, C. and Bhatia, V. (2009) Awareness of risk factors and aspects of breast cancer among north In- dian women. The Internet Journal of Health, 8, 21.

[2] American Cancer Society (2011) Breast cancer facts and figures.

http://www.cancer.org/acs/groups/content/@epidemiolog ysurveilance/documents/document/acspc030975.pdf

[3] Adebamowo, C.A. and Ajayi, O.O. (2000) Breast cancer in Nigeria. West African Journal of Nursing, 19, 179-191.

[4] Grunfeld, E.A., Ramirez, A.J., Hunter, M.S. and Richards, M.A. (2002) Women's knowledge and beliefs regarding breast cancer. British Journal of Cancer, 86, 1373-1378. doi:10.1038/sj.bjc.6600260

[5] Okobia, M.N. and Osime, U. (2001) Clinicopathological study of carcinoma of the breast in Benin City. African Journal of Reproductive Health, 5, 56-62. doi:10.2307/3583430

[6] Parkin, D.M., Bray, F., Ferlay, J. and Risani P. (2002) Global Cancer Statistics, 55, 74-10.

[7] Rosenberg, R. and Levy-Schwartz, R. (2003) Breast cancer in women younger than 40 years. International Journal of Fertility and Women's Medicine, 48, 200-2005.

[8] Saghir, N.S. (1997) Breast cancer screening: Recommendations and controversies. Lebanese Medical Journal, 45, 2000-2005.

[9] American Cancer Society (2008) Breast cancer facts and figures.

http://www.cancer.org/research/cancerfactsfigures/breast cancerfactsfigures/breast-cancer-facts--figures-2007-2008

[10] Siahpush, M. and Singh, G.K. (2002) Sociodemographic predictors of Pap test receipt, currency and knowledge among Australian women. Preventive Medicine, 35, 362368.

[11] Levshin, V., Fedichkina, T. and Droggachih, V. (2005) The experience of breast cancer screening. European Journal of Cancer, 34, 95-96. doi:10.1016/S0959-8049(98)80387-0

[12] Ludwick, R. and Gaczkowski, T. (2001) Breast self-examination by teenagers. Cancer Nursing, 24, 315-319. doi:10.1097/00002820-200108000-00013

[13] Budden, L. (1995) Young women's breast self-examination knowledge and practice. Journal of Community Health Nursing, 12, 23-32. doi:10.1207/s15327655jchn1201_3

[14] Milaat, W.A. (2000) Knowledge of secondary school female students on breast cancer and breast self examination. In Jeddah, Saudi Arabia. Eastern Mediterranean Health Journal, 6, 338-344. 